EFFECTIVENESS BULLETIN

\title{
Effective health care: management of head and neck cancers
}

\author{
R Collins, A Flynn, A Melville, R Richardson, A Eastwood
}

Qual Saf Health Care 2005;14:144-148. doi: 10.1136/qshc.2005.013961

The management of head and neck cancer, published in a recent issue of Effective Health Care, is reviewed.

$\mathrm{T}$ his article is based on a recent issue of Effective Health Care which focused on the research evidence for the management of head and neck cancers. ${ }^{1}$ The bulletin is based on a series of systematic reviews carried out by the Centre for Reviews and Dissemination to inform service guidance for head and neck cancer. Full details are provided in "Improving Outcomes in Head and Neck Cancers - The Manual" published by the National Institute for Clinical Excellence $(\mathrm{NICE})^{2}$ and "Improving Outcomes in Head and Neck Cancers - The Research Evidence". ${ }^{3}$

\section{NATURE OF THE EVIDENCE}

In general the quality of research identified for many of the systematic review questions was poor. In many areas randomised controlled trials (RCTs) have not been undertaken and either only observational studies exist or no studies could be identified at all. The review questions addressed issues throughout the patient journey of cancer detection, diagnosis and treatment.

\section{BACKGROUND}

Head and neck cancer includes cancers originating in over 30 specific anatomical sites; the majority occur in the surface layers of the upper aerodigestive tract (UAT): the mouth, lip and tongue (oral cavity), the upper part of the throat and respiratory system (pharynx) and the voice box (larynx). These cancers are most common among smokers, especially those who also consume large quantities of alcohol. This article also covers cancer of the thyroid since the services required for thyroid cancer patients overlap with those required for head and neck cancer patients; however, UAT and thyroid cancers differ in many ways. There are over 8000 new cases and 2700 deaths from head and neck and thyroid cancer each year in England and Wales. ${ }^{45}$

The prognosis for individual patients depends heavily on the site and stage of the disease at diagnosis and any pre-existing co-morbidities. Two year survival for stage I (early) UAT cancer is around $90 \%$, whilst for stage IV (more extensive or metastatic disease) it is around $50 \% .{ }^{6}$

Correspondence to: R Collins, Centre for Reviews and Dissemination, University of York, York YO10 5DD, UK; rcl4@york.ac.uk

\section{REFERRAL}

\section{Early detection of malignancy}

Patients whose cancers are detected later require more extensive treatment and experience poorer outcomes. An interview based Brazilian study reported that $58 \%$ of delays were caused by patients delaying consultation with health professionals. ${ }^{7}$ Health professionals were solely responsible for delay in $13 \%$ of cases and responsible for at least some of the delay in a further $11 \%$ of cases. The study also found that patients who did not delay in reporting symptoms to a professional were approximately half as likely to present with late stage disease. There was a dramatic increase in hospital costs with more advanced disease.

An audit conducted in the West of Scotland region found that late stage presentation was common. ${ }^{8}$ Patients presenting with stage I disease fared significantly better than those presenting with all other stages in terms of disease-free interval after treatment. They also had a significantly better overall survival rate than patients presenting with stage III or IV disease.

\section{Opportunistic screening}

A UK study of the feasibility of systematic examination of the oral mucosa by dentists concluded that this could be carried out as part of a routine dental inspection.' However, the study participants were a specific subpopulation and the study was not carried out in an NHS setting.

\section{Rapid access to a specialist/dedicated diagnostic clinic Persistent hoarseness}

Among 271 patients who attended a direct referral, immediate access hoarse voice clinic, the average waiting time for attendance at the clinic was 3 weeks. ${ }^{10}$ Thirty nine patients (14\%) were found to have suspicious lesions on indirect laryngoscopy at the clinic and were admitted for direct laryngoscopy and biopsy under anaesthetic. Ten of these 39 patients were diagnosed with cancer of the larynx, three were diagnosed with dysplasia, and one with cancer of the tongue. An audit of 34 patients referred to a pilot "husky voice" clinic with agreed referral protocols reported that $94 \%$ of patients were seen within 5 working days and five referrals (15\%) were inappropriate. ${ }^{11}$ One case of cancer was reported.

\section{Lump clinics}

Two cohorts of 50 patients referred to a "lump and bump" clinic were compared in a controlled study. The mean time between the date of the referral letter and the outpatient appointment increased from 13.8 days to 25.4 days after implementation of the 2 week wait initiative. ${ }^{12}$ 
The pick-up rate for malignancy was $4 \%$ in patients referred via the 2 week wait initiative and 14\% for non-2 week wait "lump and bump" clinic patients.

An audit and re-audit of a "one-stop" head and neck lump clinic suggest that such clinics may enable the majority of patients to be managed during a single visit with an acceptable waiting time at the clinic and a high rate of accuracy of the immediate FNAC assessment. ${ }^{13}{ }^{14}$

Of 100 patients referred to a direct referral clinic for a neck mass for which practitioners were advised of the appropriate route of referral, two referrals were considered to be inappropriate. ${ }^{15}$ Ten of 46 patients referred with enlarged lymph nodes were found to have squamous cell carcinoma and three had lymphoma. Four of 21 thyroid swellings and two of 17 salivary gland swellings were malignant.

\section{STRUCTURE OF THE SERVICE}

\section{Role of multidisciplinary teams (MDTs)}

Professionals seem to value the opportunities afforded by the MDT system. ${ }^{16}{ }^{17}$ Where appropriate procedures are in place, good clinical outcomes may be promoted by management by a MDT. ${ }^{18}$

It is generally accepted that a wide range of specialist support services should be provided. Although there is consensus that speech and language therapists, dietitians, specialist nurses, and restorative dentists can play crucial roles, the limited evidence found in this area was of poor quality and definitive conclusions cannot be drawn.

Speech and language therapists (SLTs)

Three surveys of patients who had undergone a laryngectomy suggest that patients feel that they benefit from the opportunity to see SLTs both before and after surgery. ${ }^{19-21}$

\section{Dietitians}

Two studies suggest that interventions which may be advised by dietitians or nutritionists have beneficial effects on patients. $^{22}{ }^{23}$

\section{Specialist nurses}

A cost comparison study suggested cost benefits of subspecialisation in nursing; however, no patient outcomes were measured. $^{24}$

\section{Volume and outcomes \\ Clinician volume}

In patients who underwent thyroid surgical procedures between 1991 and 1996, the complication rate for nonunilateral subtotal thyroidectomy procedures was significantly higher in patients treated by surgeons who operated on fewer than 10 patients in the study period than in those whose surgeons operated on more than 100 patients in the study period..$^{25}$ The length of hospital stay was lower in patients treated by surgeons who operated on more than 100 patients than any of the other volume categories for all surgical procedures; the difference was statistically significant in almost every category.

\section{Hospital volume}

In a retrospective survey of Scottish cancer registry data from 1984 to 1990, the effects of hospital volume were examined by comparing the largest provider with the remaining providers. ${ }^{8}$ The high volume provider saw $124(60 \%)$ of the total 206 patients. The remaining $40 \%$ of patients were treated in 13 units. Patients treated at the high volume provider had a significantly lower risk of death and a significantly lower risk of recurrence. This association between treatment centre and survival or risk of recurrence was not apparent when the treatment strategy was included as a covariate. This suggests that the improvement in outcomes for patients seen in the high volume provider may, in part at least, be related to the choice of treatments offered.

\section{DIAGNOSIS AND ASSESSMENT \\ Fine needle aspiration cytology in patients with symptoms suggestive of thyroid cancer}

In a study investigating whether core needle biopsy (CNB) provides additional information over fine needle aspiration biopsy (FNAB), 29 patients diagnosed as having thyroid nodules on ultrasound had both index tests, as well as a definitive histological diagnosis after surgery. ${ }^{26}$ However, 13 CNBs did not provide sufficient material for diagnosis so the respective accuracy of the tests is only reported for 16 patients. The sensitivity of FNAB was $86 \%$ and the specificity was $100 \%$. The sensitivity and specificity of CNB were both $100 \%$. The fact that diagnostic conclusions could only be drawn from $55 \%$ of CNBs, in contrast to $100 \%$ of FNABs, suggests that the overall efficacy of FNAB is probably superior. However, the risk of false negatives needs to be acknowledged. Due to the small sample size, this study should be regarded as suggestive rather than definitive.

\section{Effectiveness of imaging in assessing chest involvement}

Studies of the diagnostic accuracy of imaging to assess chest involvement suggest that $\mathrm{CT}$ is more likely to identify a tumour when it is present (more sensitive), but that it is also slightly more likely to falsely identify a tumour that is not present (less specific) than plain film chest radiography..$^{27}$ However, given the methodological limitations in the two identified studies, the results should be interpreted with caution.

\section{Nutritional assessment}

Early nutritional assessment and intervention, including PEG insertion, appears to be effective in preventing weight loss and dehydration in head and neck cancer patients undergoing radiotherapy. ${ }^{23} 29$

\section{Dental assessment}

Dental assessment before radiotherapy for head and neck cancer has been found to be beneficial. The majority of patients in four studies required dental treatment before the commencement of radiotherapy. ${ }^{30-33}$ Radiotherapy can cause adverse effects on the jaw, teeth and oral cavity, such that specialised dental management may also be required after treatment. $^{34}$

\section{Written information}

Written information may be helpful to patients and improve recall rates although, when used in combination with other means of communication, the relative effects of the various different methods cannot be identified. ${ }^{35-38}$

\section{Provision of a patient visitor}

Patients who have undergone laryngectomy are keen to have contact with rehabilitated patients who have previously undergone the same procedures. ${ }^{16}{ }^{17}{ }^{19-2136}$ The individual preferences of the patient should be taken into account in deciding the timing of the meeting.

\section{TREATMENT}

\section{Primary treatment}

The evidence suggests that concomitant chemotherapy increases survival and locoregional control for patients with locally advanced head and neck cancer, ${ }^{39-42}$ but no statistically significant survival benefit has been demonstrated with adjuvant or neoadjuvant chemotherapy ${ }^{42}{ }^{43}$ (other than in a subgroup analysis which detected significantly improved 
survival with neoadjuvant chemotherapy using 5-fluorouracil in combination with either cisplatin or carboplatin).$^{43}$ The evidence relating to specific agents is contradictory with regard to the efficacy of platinum-based chemoradiation. ${ }^{39-41}$ The use of concomitant chemotherapy has been found to increase both acute and late radiation morbidity effects significantly. ${ }^{44}$

Patients with newly diagnosed locally advanced nasopharyngeal cancer treated with chemoradiation had significantly higher rates of disease-free survival than patients treated with radiotherapy alone. ${ }^{45}$ This was found for neoadjuvant chemotherapy, concurrent chemotherapy, and concurrent adjuvant chemotherapy.

In patients with newly diagnosed, locally advanced head and neck cancer, 2 year locoregional control rates were higher in patients receiving accelerated radiotherapy with a concomitant boost or hyperfractionated radiotherapy than those receiving accelerated radiotherapy with a split course or conventional treatment. However, overall survival was not statistically significantly different between the arms. ${ }^{46} 47$ Trials have reported increased acute toxicity with accelerated radiotherapy compared with conventional radiotherapy. Hyperfractionated radiotherapy has been associated with increased mucosal and skin toxicity compared with conventional radiotherapy. A reduction in the risk of death has been found in patients receiving hyperfractionated radiotherapy over those receiving conventional radiotherapy in one review; ${ }^{48}$ patients treated with hyperfractionation were less likely to respond incompletely to treatment or to suffer local recurrence.

\section{Adherence to specified radiotherapy time scales}

Prolonged overall treatment time results in worse locoregional control and disease-free survival. ${ }^{49-52}$ In a re-analysis of data from the conventional arm of the CHART trial, ${ }^{50}$ patients receiving radiotherapy for 49 days or more (mean 51.5 days) had an increase in relative risk of death of $19 \%$ compared with patients receiving radiotherapy for 48 days or fewer (mean 45.7 days). When adjusted for factors collected before treatment, the increase in risk of death was $9 \%$.

Compliance with the prescribed radiotherapy schedule is relatively poor with an agreement between overall and ideal treatment time in only around $30 \%$ of cases. ${ }^{53}{ }^{54}$ A re-analysis of data from two RCTs identified a time factor of 0.8 Gy per day as the extra dose required to counteract the reduction in tumour control probability with extension of the treatment time. ${ }^{54}$ Despite the theoretical nature of the calculations, the results appear to be valid.

\section{Delays in initiating radiotherapy}

Delays in the initiation of either primary radiotherapy or postoperative radiotherapy are associated with lower rates of local control in head and neck cancer. ${ }^{55}$

\section{Interventions for the prevention and/or treatment of mucositis}

The evidence relating to head and neck cancer patients suggests that the use of prophylactic narrow spectrum antibiotics is beneficial for preventing severe oral mucositis in patients receiving radiotherapy. ${ }^{56}$ Amifostine was beneficial in patients undergoing chemoradiotherapy; it did not affect the antitumour effectiveness of radiotherapy and it rarely produced severe adverse effects. It was not found to significantly benefit head and neck cancer patients undergoing radiotherapy without concurrent chemotherapy. ${ }^{57}$

In cancer patients receiving chemotherapy or radiotherapy, ice chips and GM-CSF prevented mucositis and antibiotic paste or pastille and amifostine provided moderate and minimal benefits in preventing mucositis, respectively. ${ }^{58}$ Hydrolytic enzymes reduced the severity of mucositis.

\section{Interventions to reduce the severity of the symptoms} of xerostomia

In three systematic reviews pilocarpine hydrochloride and amifostine were found to significantly reduce the effects of radiation induced xerostomia (dry mouth) in patients with head and neck cancer. ${ }^{57-60}$ Adverse effects of both agents were common but not severe or life threatening. However, these conclusions should be interpreted with caution owing to the lack of information about the methods used in two of the reviews and possible heterogeneity between included studies.

\section{Palliative treatment}

Chemotherapy, given in combination with radiotherapy, may significantly improve disease-free survival in previously untreated patients being treated palliatively for oropharyngeal cancers (stages III-IV) in the short term. One relatively small study found that the complete response rate of patients treated by chemoradiotherapy was 39\% higher than that of patients treated by radiotherapy alone. ${ }^{61}$ This difference was statistically significant $(p=0.015)$. However, more research is required to assess longer term benefits.

\section{REHABILITATION SERVICES}

\section{Speech and language therapy}

The majority of studies identified relating to speech and language therapy were retrospective in nature, with potential biases. ${ }^{19}{ }^{62-72}$ However, questionnaire based studies and case series reports support the view that speech and language therapy is beneficial in the rehabilitation of patients with head and neck cancer.

\section{Osseointegrated implants}

A number of studies have investigated the outcomes of dental and facial bone restoration using prostheses fixed to osseointegrated implants. ${ }^{73-81}$ It appears that the probability of osseointegration may be reduced in patients who have had radiotherapy, ${ }^{73-75}$ although the evidence was contradictory. ${ }^{76}{ }^{77}$ Some evidence exists which suggests that hyperbaric oxygen therapy may ameliorate the effect of radiotherapy on osseointegration. ${ }^{74}$ Chemotherapy does not appear adversely to affect the success of osseointegration. ${ }^{79-81}$ While treatment related factors have an important influence on the outcome of osseointegration procedures, it appears that anatomical factors may play an especially important role. Grafted bone appears to be more likely to permit osseointegration than local bone and integration is more likely in the mandible than in the maxilla. ${ }^{75}$ However, in view of the potential biases in these studies, their conclusions may not be reliable.

\section{Patient support groups and education groups}

Three surveys and a case series suggest that patients who are members of support groups derive benefits from their membership. ${ }^{16}{ }^{1782-84}$ A before and after study of patients who attended a monthly educational self-help group ${ }^{85}$ and a small qualitative study of patients who attended a l week psychoeducational programme a year after diagnosis ${ }^{86}$ reported that patients were satisfied with the group and learned new things.

\section{FOLLOW UP}

\section{Routine follow up}

One systematic review was identified that assessed 37 different strategies for following up patients treated for UAT cancer. ${ }^{87}$ These strategies were either common to all forms of UAT cancer $(n=12)$ or specific to individual UAT cancers $(n=25)$. Every strategy recommended follow up clinic consultations for detecting deterioration in the status of the patient. Chest radiographs were recommended by 10 general strategies and 21 site-specific ones. Blood counts and 


\section{Implications}

The results of the systematic reviews presented above were used to inform the production of the service guidance for head and neck cancer. ${ }^{2} 3$ The following key recommendations have been identified as priorities for the NHS, with the aim of improving outcomes in head and neck cancers:

- Services for patients with head and neck cancers should be commissioned at the Cancer Network level.

- Multidisciplinary teams with a wide range of specialists will be central to the service, each managing at least 100 new cases of upper aerodigestive tract cancer per annum. Specialised teams will deal with patients with thyroid cancer and those with rare conditions.

- Arrangements for referral at each stage of the patient's cancer journey should be streamlined. Diagnostic clinics should be established for patients with neck lumps.

- A wide range of support services should be provided.

- Coordinated local support teams should be established to provide long term support and rehabilitation for patients in the community.

- Multidisciplinary teams should take responsibility for ensuring that accurate and complete data on disease stage, management, and outcomes are recorded.

- Research into the effectiveness of managementincluding assessment, treatment, delivery of services and rehabilitation - urgently requires development and expansion.

liver function tests were the only other tests widely recommended. The review reported few details about its methods or the included studies and did not present any evidence on the effectiveness of different follow up strategies.

\section{Imaging in the detection of recurrence}

Overall, the evidence reviewed showed both magnetic resonance imaging (MRI) and positron emission tomography (PET) to be more accurate than computed tomographic (CT) scanning, colour Doppler echography (CDE), and ultrasound in detecting recurrence in head and neck cancers. ${ }^{88-92}$

A well conducted diagnostic study compared CT scanning with MRI and found both to have relatively low sensitivity (44-67\% for CT and 56\% for MRI) and moderate specificity (64-69\% for CT and $78-83 \%$ for MRI) in detecting tumour recurrence and in distinguishing recurrence from postradiation therapy changes. However, MRI was found to be more accurate than CT (73-78\% compared with $64 \%){ }^{88}$

Two studies which compared CT with PET in patients with a suspected recurrence found that PET was more accurate than CT. ${ }^{89}{ }^{90}$ A study which compared CT, PET and CDE found that the accuracy of CT and CDE were comparable at $79 \%$ each, but the accuracy of PET was superior at $86 \% .^{91}$ In a study which compared ultrasound with PET, PET was found to be more accurate than ultrasound ( $86 \%$ versus $64 \%) .{ }^{92}$

\section{Authors' affiliations}

R Collins, A Eastwood, Centre for Reviews and Dissemination, University of York, York, UK

A Flynn, Clinical Oncology and Radiotherapy, Guy's and St Thomas' NHS Foundation Trust, London, UK

A Melville, 22 West End Parade, Pwllheli, Gwynedd LL53 5PN, UK R Richardson, Department of Health Sciences, University of York, York, UK

\section{REFERENCES}

1 Centre for Reviews and Dissemination. Management of head and neck cancers. Effective Health Care 2004;8:5

2 National Institute for Clinical Excellence (NICE). Guidance on cancer services: improving outcomes in head and neck cancers: the manual. London: NICE, 2004.

3 Centre for Reviews and Dissemination. Guidance on cancer services: improving outcomes in head and neck cancers: the research evidence. York: Centre for Reviews and Dissemination, 2004.

4 Office of National Statistics. Data provided on request by the Office of National Statistics (ONS). London: ONS, 2002.

5 Welsh Cancer Intelligence \& Surveillance Unit. Data provided on request by the Welsh Cancer Intelligence \& Surveillance Unit, 2002.

6 South West Cancer Intelligence Service (SWICS). Second head and neck audit report. Bristol: SWICS, 2001

7 Kowalski LP, Franco EL, Torloni $\mathrm{H}$, et al. Lateness of diagnosis of oral and oropharyngeal carcinoma: factors related to the tumour, the patient and health professionals. Eur J Cancer B Oral Oncol 1994;3:167-73.

8 Robertson AG, Robertson C, Soutar DS, et al. Treatment of oral cancer: the need for defined protocols and specialist centres. Variations in the treatment of oral cancer. Clin Oncol 2001;13:409-15.

9 Field EA, Morrison T, Darling AE, et al. Oral mucosal screening as an integral part of routine dental care. Br Dent J 1995;179:262-6.

10 Hoare TJ, Thomson HG, Proops DW. Detection of laryngeal cancer: the case for early specialist assessment. J R Soc Med 1993;86:390-2.

11 Resouly A, Hope A, Thomas S. A rapid access husky voice clinic: useful in diagnosing laryngeal pathology. J Laryngol Otol 2001;115:978-80.

12 McCombe A, George E. One-stop neck lump clinic. Clin Otolaryngol 2002:27.

13 Murray A, Stewart CJ, McGarry GW, et al. Patients with neck lumps: can they be managed in a 'one-stop' clinic setting? Clin Otolaryngol 2000;25:471-5.

14 Kishore A, Stewart CJ, McGarry GW, et al. One-stop neck lump clinic: phase 2 of audit. How are we doing? Clin Otolaryngol 2001;26:495-7.

15 Vowles RH, Ghiacy S, Jefferis AF. A clinic for the rapid processing of patients with neck masses. J Laryngol Otol 1998;112:1061-4.

16 Edwards D. Face to face. London: King's Fund, 1997

17 Edwards D. Head and neck cancer services: views of patients, their families and professionals. Br J Oral Maxillofac Surg 1998;36:99-102.

18 Anton JV, Gstöttner W, Matula C. Interdisciplinary surgical treatment of anterior skull base tumors. Wien Klin Wochenschr 1999;111:560-7.

19 Lehmann W, Krebs H. Interdisciplinary rehabilitation of the laryngectomee. Recent Results Cancer Res 1991;121:442-9.

20 Johnson JT, Casper J, Lesswing NJ. Toward the total rehabilitation of the alaryngeal patient. Laryngoscope 1979;89:1813-9.

21 Minear D, Lucente FE. Current attitudes of laryngectomy patients. Laryngoscope 1979;89:1061-5.

22 Flynn MB, Leightty FF. Preoperative outpatient nutritional support of patients with squamous cancer of the upper aerodigestive tract. Am J Surg 1987; 154:359-62.

23 Piquet MA, Ozsahin M, Larpin I, et al. Early nutritional intervention in oropharyngeal cancer patients undergoing radiotherapy. Support Care Cancer 2002:10:502-4.

24 Seikaly H, Calhoun KH, Stonestreet JS, et al. The impact of a skilled nursing facility on the cost of surgical treatment of major head and neck tumors. Arch Otolaryngol Head Neck Surg 2001;127:1086-8.

25 Sosa JA, Bowman HM, Tielsch JM, et al. The importance of surgeon experience for clinical and economic outcomes from thyroidectomy. Ann Surg 1998;228:320-30.

26 Pisani T, Bononi $M$, Nagar $C$, et al. Fine needle aspiration and core needle biopsy techniques in the diagnosis of nodular thyroid pathologies. Anticancer Res 2000;20:3843-7.

27 Warner GC, Cox GJ. Evaluation of chest radiography versus chest computed tomography in screening for pulmonary malignancy in advanced head and neck cancer. Am J Otolaryngol 2003;32:107-9.

28 Arunachalam PS, Putnam G, Jennings $P$, et al. Role of computerized tomography (CT) scan of the chest in patients with newly diagnosed head and neck cancers. Clin Otolaryngol 2002;27:409-11.

29 Lees J. Nasogastric and percutaneous endoscopic gastrostomy feeding in head and neck cancer patients receiving radiotherapy treatment at a regional oncology unit: a two year study. Eur J Cancer Care 1997;6:45-9.

30 Lizi EC. A case for a dental surgeon at regional radiotherapy centres. Br DentJ 1992;173:24-6.

31 Epstein JB, Emerton S, Lunn R, et al. Pretreatment assessment and dental management of patients with nasopharyngeal carcinoma. Oral Oncol 1999;35:33-9.

32 Brown RS, Miller JH, Bottomley WK. A retrospective oral/dental evaluation of 92 head and neck oncology patients, before, during and after irradiation therapy. Gerodontology 1990;9:35-9.

33 Lockhart PB, Clark J. Pretherapy dental status of patients with malignant conditions of the head and neck. Oral Surg Oral Med Oral Pathol 1994;77:236-41.

34 Horiot JC, Bone MC, Ibrahim E, et al. Systematic dental management in head and neck irradiation. Int J Radiat Oncol Biol Phys 1981;7:1025-9.

35 Chan Y, Irish JC, Wood SJ, et al. Patient education and informed consent in head and neck surgery. Arch Otolaryngol Head Neck Surg 2002; 128:1269-74.

36 Feber T. Design and evaluation of a strategy to provide support and information for people with cancer of the larynx. Eur J Oncol Nurs 1998;2:106-14. 
37 Clarke A. Resourcing and training head and neck cancer nurse specialists to deliver a social rehabilitation programme to patients. D Clin Psychol, City University, 2001.

38 Semple C, Allam C. Providing written information for patients with head and neck cancer. Prof Nurse 2002;17:620-2.

39 Browman GP, Hodson DI, Mackenzie RG, et al. Concomitant chemotherapy and radiotherapy in squamous cell head and neck cancer lexcluding nasopharynx). Practice guideline 5-6a. Cancer Care Ontario Practice Guideline Initiative, 2000. Available at http://www.cancercare.on.ca/pdf/ full5_6a.pdf.

40 Browman GP, Hodson DI, Mackenzie RJ, et al. Choosing a concomitant chemotherapy and radiotherapy regimen for squamous cell head and neck cancer: a systematic review of the published literature with subgroup analysis. Head Neck 2001;23:579-89.

41 Munro AJ. An overview of randomised controlled trials of adjuvant chemotherapy in head and neck cancer. Br J Cancer 1995;71:83-91.

42 Pignon JP, Bourhis J, Domenge C, et al. Chemotherapy added to locoregional treatment for head and neck squamous-cell carcinoma: three meta-analyses of updated individual data. Lancet 2000;355:949-55.

43 Browman GP, Charette M, Oliver T, et al. Neoadjuvant chemotherapy in locally advanced squamous cell carcinoma of the head and neck (SCCHN) (excluding nasopharynx). Practice Guideline 5-1. Cancer Care Ontario Practice Guideline Initiative, 2003. Available at http:// www.cancercare.on.ca/pdf/sumry5_1.pdf.

44 Henk JM. Controlled trials of synchronous chemotherapy with radiotherapy in head and neck cancer: overview of radiation morbidity. Clin Oncol 1997;9:308-12.

45 Thephamongkhol K, Browman GP, Hodson DI, et al. The role of chemotherapy with radiotherapy in the management of patients with newly diagnosed locally advanced squamous cell or undifferentiated nasopharyngeal cancer. Practice Guideline 5-7, Cancer Care Ontario Practice Guideline Initiative, 2003. Available at http:// www.cancercare.on.ca/pdf/pebc5-7f.pdf.

46 Mackenzie RG. Accelerated radiotherapy for locally advanced squamous cell carcinoma of the head and neck. Practice Guideline 5-6c. Cancer Care Ontario Practice Guideline Initiative, 2003. Available at http:// www.cancercare.on.ca/pdf/sumry5_6c.pdf.

47 Mackenzie RG, Hodson DI, Head and Neck Cancer Diseases Site Group. Hyperfractionated radiotherapy for locally advanced squamous cell carcinoma of the head and neck. Practice Guideline 5-6b. Cancer Care Ontario Practice Guideline Initiative, 2003. Available at http:// www.cancercare.on.ca/pdf/sumry5 6b.pdf.

48 Stuschke M, Thames HD. Hyperfractionated radiotherapy of human tumors overview of the randomized clinical trials. Int J Radiat Oncol Biol Phys 1997;37:259-67.

49 Robertson AG, Robertson C, Perone C, et al. Effect of gap length and position on results of treatment of cancer of the larynx in Scotland by radiotherapy: a linear quadratic analysis. Radiother Oncol 1998;48:165-73.

50 Robertson G, Parmar M, Foy C, et al. Overall treatment time and the conventional arm of the CHART trial in the radiotherapy of head and neck cancer. Radiother Oncol 1999;50:25-8.

51 Robertson C, Robertson AG, Hendry JH, et al. Similar decreases in local tumor control are calculated for treatment protraction and for interruptions in the radiotherapy of carcinoma of the larynx in four centers. Int J Radiat Oncol Biol Phys 1998;40:319-29.

52 Kwong DL, Sham JS, Chua DT, et al. The effect of interruptions and prolonged treatment time in radiotherapy for nasopharyngeal carcinoma. Int J Radiat Oncol Biol Phys 1997;39:703-10.

53 Khalil AA, Bentzen SM, Bernier J, et al. Compliance to the prescribed dose and overall treatment time in five randomized clinical trials of altered fractionation in radiotherapy for head-and-neck carcinomas. Int J Radiat Oncol Biol Phys 2003;55:568-75.

54 Roberts SA, Hendry JH, Brewster AE, et al. The influence of radiotherapy treatment time on the control of laryngeal cancer: a direct analysis of data from two British Institute of Radiology trials to calculate the lag period and the time factor. Br J Radiol 1994;67:790-4.

55 Huang J, Barbera L, Brouwers $M$, et al. Does delay in starting treatment affect the outcomes of radiotherapy? A systematic review. J Clin Oncol 2003;21:555-63.

56 Sutherland SE, Browman GP. Prophylaxis of oral mucositis in irradiated headand-neck cancer patients: A proposed classification scheme of interventions and meta-analysis of randomized controlled trials. Int J Radiat Oncol Biol Phys 2001;49:917-30.

57 Hodson DI, Browman GP, Thephamongkhol K, et al. The role of amifostine as a radioprotectant in the management of patients with squamous cell head and neck cancer. Practice Guideline 5-8. Cancer Care Ontario Practice Guideline Initiative, 2003. Available at http://www.cancercare.on.ca/pdf/ pebc5-8f.pdf.

58 Clarkson JE, Worthington HV, Eden OB. Interventions for preventing oral mucositis for patients with cancer receiving treatment (Cochrane Review). The Cochrane Library. Issue 2. Chichester, UK: John Wiley \& Sons Ltd, 2003.

59 Hawthorne M, Sullivan K. Pilocarpine for radiation-induced xerostomia in head and neck cancer. Int J Palliat Nurs 2000;6:228, 30-2.

60 Hodson DI, Haines T, Berry M, et al. Symptomatic treatment of radiationinduced xerostomia in head and neck cancer patients. Practice guideline 5-5. Cancer Care Ontario Practice Guideline Initiative; 2002. Available at http:// www.cancercare.on.ca/pdf/full5_5.pdf.
61 Smid L, Lesnicar H, Zakotnik B, et al. Radiotherapy, combined with simultaneous chemotherapy with mitomycin $C$ and bleomycin for inoperable head and neck cancer - preliminary report. Int J Radiat Oncol Biol Phys 1995;32:769-75.

62 de Maddalena $\mathrm{H}$, Pfrang $\mathrm{H}$. Improvement of communication behavior of laryngectomized and voice-rehabilitated patients by a psychological training program. HNO 1993;41:289-95.

63 Sittel C, Eckel HE, Eschenburg C. Phonatory results after laser surgery for glottic carcinoma. Otolaryngol Head Neck Surg 1998;119:418-24.

64 Sittel C, Eckel HE, Eschenburg C, et al. Voice quality after partial laser laryngectomy. Laryngorhinootologie 1998;77:219-25.

65 Bachher GK, Dholam K, Pai PS. Effective rehabilitation after partial glossectomy. Indian J Otolaryngol 2002;54:39-43.

66 Hocevar-Boltezar I, Smid L, Zargi M, et al. Factors influencing rehabilitation in patients with head and neck cancer. Radiother Oncol 2000;34:289-94.

67 Dejonckere PH. Functional swallowing therapy after treatment for head and neck cancer can outcome be predicted? Rev Laryngol Otol Rhinol (Bord) 1998; 119:239-43.

68 Perry AR, Shaw MA. Evaluation of functional outcomes (speech, swallowing and voice) in patients attending speech pathology after head and neck cancer treatment(s): development of a multi-centre database. J Laryngol Otol 2000;114:605-15.

69 Meyerson MD, Johnson BH, Weitzman RS. Rehabilitation of a patient with complete mandibulectomy and partial glossectomy. Am J Otolaryngol 1980;1:256-61.

70 Logemann JA, Pauloski BR, Rademaker AW, et al. Speech and swallowing rehabilitation for head and neck cancer patients. Oncology 1997;1 1:651-64.

71 Gates GA, Ryan W, Cooper JC, et al. Current status of laryngectomee rehabilitation: I. Results of therapy. Am J Otolaryngol 1982;3:1-7.

72 Smithwick L, Davis P, Dancer J, et al. Female laryngectomees' satisfaction with communication methods and speech-language pathology services. Percept Mot Skills 2002;94:204-6

73 Weischer T, Mohr C. Ten-year experience in oral implant rehabilitation of cancer patients: treatment concept and proposed criteria for success. Int J Oral Maxillofac Implants 1999; 14:521-8.

74 Granstrom G, Tjellstrom A, Branemark PI. Osseointegrated implants in irradiated bone: a case-controlled study using adjunctive hyperbaric oxygen therapy. J Oral Maxillofac Surg 1999:57:493-9.

75 Goto M, Jin-Nouchi S, Ihara K, et al. Longitudinal follow-up of osseointegrated implants in patients with resected jaws. Int J Oral Maxillofac Implants 2002; 17:225-30.

76 Esser E, Wagner W. Dental implants following radical oral cancer surgery and adjuvant radiotherapy. Int J Oral Maxillofac Implants 1997;12:552-7.

77 Wagner W, Esser E, Ostkamp K. Osseointegration of dental implants in patients with and without radiotherapy. Acta Oncol 1998:37:693-6.

78 Granstrom G, Tjellstrom A, Branemark PI, et al. Bone-anchored reconstruction of the irradiated head and neck cancer patient. Otolaryngol Head Neck Surg 1993; 108:334-43.

79 Kovacs AF. The fate of osseointegrated implants in patients following oral cancer surgery and mandibular reconstruction. Head Neck 2000;22:111-9.

80 Kovacs AF. Assessment of prosthetic restorations on bone-lock implants in patients after oral tumor resection. Int J Oral Implantol 1998;24:101-9.

81 Kovacs AF. Influence of chemotherapy on endosteal implant survival and success in oral cancer patients. Int J Oral Maxillofac Surg 2001;30:144-7.

82 Birkhaug EJ, Aarstad HJ, Aarstad AK, et al. Relation between mood, social support and the quality of life in patients with laryngectomies. Eur Arch Otorhinolaryngol 2002;259:197-204.

83 Mathieson CM, Logan-Smith LL, Phillips J, et al. Caring for head and neck oncology patients. Does social support lead to better quality of life? Can Fam Physician 1996;42:1712-20

84 Harris LL, Vogtsberger KN, Mattox DE. Group psychotherapy for head and neck cancer patients. Laryngoscope 1985:95:585-7.

85 Hell B. First experience with a self-help group of cancer patients of the oral and maxillofacial surgery department. Dtsch Z Mund Kiefer Gesichtschir 1987; 11:234-5.

86 Hammerlid E, Persson LO, Sullivan M, et al. Quality-of-life effects of psychosocial intervention in patients with head and neck cancer. Otolaryngol Head Neck Surg 1999;120:507-16.

87 Virgo KS, Paniello RC, Johnson FE. Costs of posttreatment surveillance for patients with upper aerodigestive tract cancer. Arch Otolaryngol Head Neck Surg 1998; 124:564-72

88 Chong VF, Fan YF. Detection of recurrent nasopharyngeal carcinoma: MR imaging versus CT. Radiology 1997;202:463-70.

89 Lapela $M$, Eigtved A, Jyrkkio S, et al. Experience in qualitative and quantitative FDG PET in follow-up of patients with suspected recurrence from head and neck cancer. Eur J Cancer 2000;36:858-67.

90 Bongers V, Hobbelink MG, van Rijk PP, et al. Cost-effectiveness of dual-head F-18-fluorodeoxyglucose PET for the detection of recurrent laryngeal cancer. Cancer Biother Radiopharm 2002;17:303-6.

91 Di Martino E, Hausmann R, Krombach GA, et al. Relevance of colour-duplex echography for detection and therapy of recurrences in the follow-up of head and neck cancer. Laryngorhinootologie 2002;81:866-74

92 Goerres GW, Haenggeli CA, Allaoua M, et al. Direct comparison of F-18FDG PET and ultrasound in the follow-up of patients with squamous cell cancer of the head and neck. Nuklearmedizin 2000;39:246-50. 